\title{
Chemometric-assisted RP-HPLC method for the simultaneous determination of ambroxol hydrochloride, terbutaline sulfate, and guaiphenesin in combined dosage form
}

\author{
Keerthisikha Palur ${ }^{1 *}$, Bharathi Koganti ${ }^{2}$, Sreenivasa Charan Archakam ${ }^{1}$ \\ ${ }^{1}$ Assistant Professor, Sri Padmavathi School of Pharmacy, Tiruchanoor, India. \\ ${ }^{2}$ Professor, Sri Padmavthi Mahila University, Tirupati, India.
}

\begin{tabular}{l}
\hline ARTICLE INFO \\
\hline Received on: 01/04/2019 \\
Accepted on: 10/07/2019 \\
Available online: 01/09/2019 \\
\hline Key words: \\
Chemometric model, central \\
composite design, response \\
surface methodology, \\
Derringers' desirability \\
function.
\end{tabular}

\begin{abstract}
An isocratic reverse-phase High performance liquid chromatography (HPLC) method using a chemometric model was developed and validated for the simultaneous determination of ambroxol hydrochloride, terbutaline sulfate, and guaiphenesin in their combined dosage form. Central composite design which is a subset of response surface methodology was used as the chemometric model. The separation of three drugs was carried out by using a Phenomenex $\mathrm{C}_{18}$ column and detection at $220 \mathrm{~nm}$ using a UV detector. Based on initial trials, the three factors selected for the design were methanol $(\mathrm{MN})$ concentration, mobile phase $\mathrm{pH}$, and flow rate in the range of $55 \%-65 \%(\mathrm{v} / \mathrm{v}), 4-5$ units, and $0.6-1 \mathrm{ml} / \mathrm{min}$, respectively. The impact of the selected factors on the responses like retention time of first peak $\left(\mathrm{tR}_{1}\right)$, resolution of $2 \mathrm{nd}$ and $3 \mathrm{rd}$ peak $\left(\mathrm{Rs}_{2,3}\right)$, and theoretical plates of the first peak $\left(\mathrm{TP}_{1}\right)$ were evaluated. Derringers' desirability function was used to optimize the responses. The conditions which were optimized for the assay of drugs were $\mathrm{MN}, \mathrm{ACN}$, and $50 \mathrm{mM} \mathrm{KH}_{2} \mathrm{PO}_{4}(\mathrm{pH} 5)$ in the ratio of 55:10:35 at a flow rate of $0.8 \mathrm{ml} /$ minute. The developed and optimized method was validated as per the International conference on harmonization (ICH) guidelines and can be used for routine analysis in quality control laboratories.
\end{abstract}

\section{INTRODUCTION}

Ambroxol hydrochloride (AMB), [trans-4-(2-Amino-3, 5-dibrombenzylamino)—cyclohexanol hydrochloride] (Fig. 1A), which belongs to the category of mucolytics, is used to decrease surfeit mucus and to treat respiratory system diseases. Guaiphenesin (GUA) is an expectorant and used to expel sputum from the respiratory tract. (Pubchem, 2018) .Chemically, it is 3-(2-methoxyphenoxy) propane-1, 2-diol. (Fig. 1B). Terbutaline sulfate (TER), tertbutyl-[2-(3, 5-dihydroxyphenyl)-2-hydroxyethyl] azanium; sulfate belongs to bronchodilator category which relaxes the vascular and bronchial muscles (Pubchem, 2018). The combination of these three

\section{${ }^{*}$ Corresponding Author}

Keerthisikha Palur, Assistant Professor,

Sri Padmavathi School of Pharmacy, Tiruchanoor, India.

E-mail: keerthi8spsp@gmail.com drugs AMB, GUA, and TER is available in an expectorant dosage form containing the drugs in divergent proportions and is specified in the treatment of chronic bronchitis and asthma.

Only two RP-HPLC and one spectrophotometric methods were reported for the analysis of three drugs in their combined dosage form (Ghosh et al., 2016; Lakshmi Narasimha Rao et al., 2014; Ritu Kimbahune et al., 2011). Hence, it was aimed to develop a RP-HPLC method using a chemometric model and to validate and apply the method for the quantification of the drugs in their dosage form.

\section{MATERIALS AND METHODS}

\section{Chemicals and reagents}

The active pharmaceutical ingredients (API) of AMB (98.9\%), TER (98.7\%), and GUA (98.7\%) were supplied by Raffles Pharmaceuticals Pvt Ltd., Tirupati. HPLC-grade methanol, acetonitrile, and analytical reagent grade potassium 


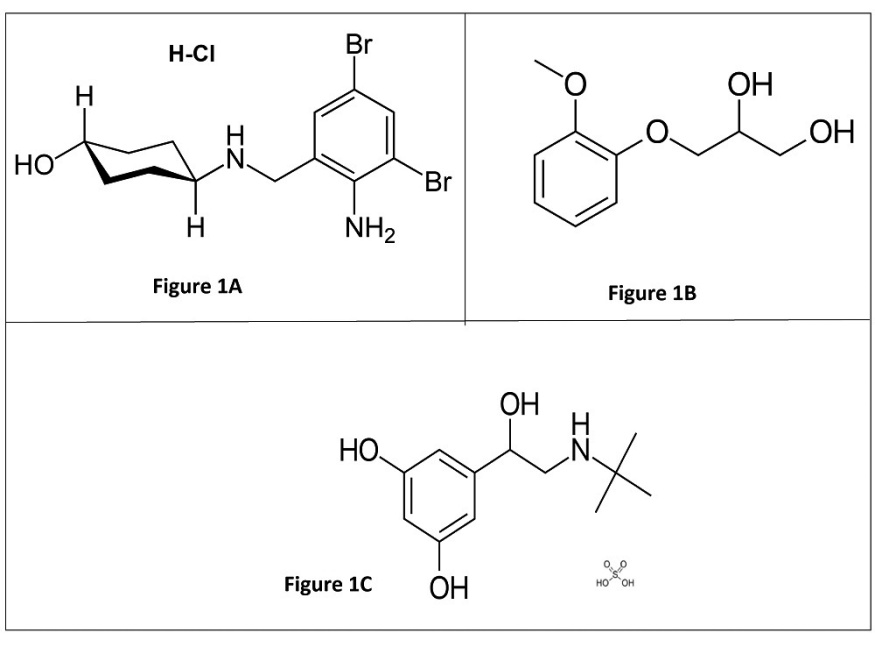

Figure 1. Chemical structures of analyte.

dihydrogen phosphate $\left(\mathrm{KH}_{2} \mathrm{PO}_{4}\right)$ and orthophosphoric acid were acquired from S.D fine chemical Ltd., Mumbai, India, and HPLC grade water from Millipore were used in the analysis. NORVENT expectorant containing AMB $15 \mathrm{mg}$, TER $1.25 \mathrm{mg}$, and GUA 50 $\mathrm{mg}$ was purchased from the local medical store.

\section{Instrumentation and software}

HPLC system used was Shimadzu Prominence LC system with LC-20AT pump with UV-VIS detector and with 20 $\mu$ l loop volume Rheodyne injector. The software used in data processing is LC Solution. An Elico pH meter (Model LI-120) was used to measure and adjust the $\mathrm{pH}$ of the buffer. Ultrasonicator (PCI Analytics) was used for degassing the solutions. Design-Expert, version 11.0.0. (Stat-Ease Inc., Minneapolis, MN) software was used to select the design for optimization of the data and for further processing.

\section{Chromatographic conditions}

RP-HPLC method was developed using a Phenomenex $\mathrm{C} 18$ analytical column $(4.5 \times 250 \mathrm{~mm}, 5 \mu)$ at room temperature with a mobile phase containing methanol (MN), acetonitrile (CAN), $50 \mathrm{mM} \mathrm{KH} \mathrm{PO}_{4}$ buffer $\mathrm{pH}$ adjusted to 5 in the ratio $55: 10: 35$ $(\mathrm{v} / \mathrm{v} / \mathrm{v})$. The flow rate of the mobile phase was $0.8 \mathrm{ml} / \mathrm{min}$. and the detection was carried using a UV detector and wavelength selected was $220 \mathrm{~nm}$. The injection volume was $20 \mu \mathrm{L}$.

\section{Preparation of stock and standard solutions}

Stock solutions of AMB, TER, and GUA containing 1 $\mathrm{mg} / \mathrm{ml}$ were prepared individually by dissolving $50 \mathrm{mg}$ in $50 \mathrm{ml}$ of methanol. A mixture containing the three standard solutions were prepared from the stock solution to get a concentration of AMB $(20 \mu \mathrm{g} / \mathrm{ml})$, TER $(20 \mu \mathrm{g} / \mathrm{ml})$, and GUA $(20 \mu \mathrm{g} / \mathrm{ml})$, respectively, using mobile phase.

\section{Preparation of phosphate buffer}

$6.8 \mathrm{gm}$ of potassium di-hydrogen orthophosphate (50 $\mathrm{mM}$ ) was dissolved in sufficient water (HPLC grade) and volume was made up to $1,000 \mathrm{ml}$. The solution was kept for sonication and $\mathrm{pH}$ was adjusted to 5.0 using orthophosphoric acid.

\section{Sample preparation}

Sample enrichment technique was used in sample preparation. Syrup sample equivalent to $20 \mathrm{mg}$ of GUA ( $2 \mathrm{ml}$ of syrup), $0.5 \mathrm{mg}$ of TER, and $6 \mathrm{mg}$ of AMB was transferred to a 50 $\mathrm{ml}$ volumetric flask containing $20 \mathrm{ml}$ of the mobile phase. To this $19.5 \mathrm{mg}$ of TER API, $14 \mathrm{mg}$ of AMB API were added and this sample solution was kept for sonication for 15 minutes and then the volume was adjusted up to the mark with mobile phase to get a concentration of $400 \mu \mathrm{g} / \mathrm{ml}$ of the three drugs. Filtration was carried out by using vacuum filter using $0.45 \mu$ filter papers. 0.5 $\mathrm{ml}$ of the filtrate was taken and transferred into a $10 \mathrm{ml}$ volumetric flask and the volume was made up to the mark with the mobile phase to get a concentration of AMB $(20 \mu \mathrm{g} / \mathrm{ml})$, TER $(20 \mu \mathrm{g} / \mathrm{ml})$, and GUA $(20 \mu \mathrm{g} / \mathrm{ml})$, respectively.

\section{Design of experiments}

The widely used chemometric model in the optimization of RP-HPLC method is the central composite design which is a subclass of response surface methodology (Giriraj et al., 2014; Sivakumar et al., 2007; Sree Janardhanan et al., 2016). In central composite design (CCD), three factors at two levels were used to optimize HPLC separation. Based on the trials performed, the factors were selected and in the variation ranges of $55-65(\% \mathrm{v} / \mathrm{v})$ of MN concentration (A), 4-5 of mobile phase $\mathrm{pH}(\mathrm{B})$, and $0.6-1.0$ $\mathrm{ml} /$ minute of flow rate $(\mathrm{C})$, respectively. The retention time of first peak $\left(\mathrm{tR}_{1}\right)$, resolution of $2 \mathrm{nd}$ and $3 \mathrm{rd}$ peak $\left(\mathrm{Rs}_{2,3}\right)$, and theoretical plates of the first peak $\left(\mathrm{TP}_{1}\right)$ were selected as responses and measured in 20 runs in randomized order according to the CCD.

\section{Method validation}

Specificity

Specificity of the method was studied for the interference of mobile phase (blank) with that of the sample chromatogram. For this, blank and sample chromatograms were compared for any interference.

\section{Linearity and Range}

The linearity of the proposed method was established at $50 \%, 70 \%, 100 \%, 130 \%$, and $150 \%$ of the target concentrations of all the drugs. Calibration curves were plotted for each drug in the range of $10-30 \mu \mathrm{g} / \mathrm{ml}$ and the regression parameters were assessed.

\section{Precision}

For the developed RP-HPLC method, both system precision and method precision were performed. System precision was carried out by injecting six replicate injections of the standard mixture at its target concentration. Various chromatographic parameters like retention time, peak area, theoretical plates, and tailing factor were assessed and their $\%$ relative standard deviation (RSD) were calculated. Method precision was carried out by injecting six replicate injections of the assay sample and \% RSD of the peak area and \% assay values were calculated.

\section{Accuracy}

Accuracy in terms of \% recovery was performed by using standard addition method for $70 \%, 100 \%$, and $130 \%$ levels of test concentration. 
Table 1. Central composite design of experiments and responses.

\begin{tabular}{ccccccc}
\hline & Factor 1 & Factor 2 & Factor 3 & Response 1 & Response 2 & Response 3 \\
\hline Run & $\mathrm{A}: \mathrm{A}$ & $\mathrm{B}: \mathrm{B}$ & $\mathrm{C}: \mathrm{C}$ & $\mathrm{tR} \mathrm{R}_{1}$ & $\mathrm{Rs}_{2,3}$ & $\mathrm{TP}_{1}$ \\
1 & 65 & 4 & 1 & 2.426 & 3.236 & 3737 \\
2 & 60 & 4.5 & 1.13636 & 2.158 & 2.848 & 3316 \\
3 & 65 & 5 & 0.6 & 4.018 & 5.919 & 4719 \\
4 & 65 & 4 & 0.6 & 4.012 & 4.345 & 5083 \\
5 & 60 & 4.5 & 0.8 & 3.038 & 3.237 & 4029 \\
6 & 68.409 & 4.5 & 0.8 & 3.036 & 3.917 & 4470 \\
7 & 55 & 4 & 0.6 & 4.006 & 2.804 & 4706 \\
8 & 60 & 4.5 & 0.8 & 3.046 & 3.235 & 4065 \\
9 & 60 & 4.5 & 0.8 & 3.046 & 3.279 & 4085 \\
10 & 60 & 4.5 & 0.8 & 3.028 & 3.224 & 4038 \\
11 & 60 & 4.5 & 0.8 & 3.04 & 3.18 & 4044 \\
12 & 60 & 4.5 & 0.463641 & 5.232 & 3.608 & 4886 \\
13 & 60 & 5.3409 & 0.8 & 3.055 & 11.959 & 4064 \\
14 & 55 & 4 & 1 & 2.431 & 2.931 & 3624 \\
15 & 55 & 5 & 0.6 & 4.085 & 12.097 & 3852 \\
16 & 60 & 4.5 & 0.8 & 3.037 & 3.233 & 4069 \\
17 & 55 & 5 & 1 & 2.454 & 9.904 & 3406 \\
18 & 60 & 3.6591 & 0.8 & 3.023 & 1.385 & 4365 \\
19 & 51.591 & 4.5 & 0.8 & 3.063 & 6.881 & 4043 \\
20 & 65 & 5 & 1 & 2.439 & 2.871 & 4126 \\
\hline
\end{tabular}

\section{RESULTS AND DISCUSSION}

\section{Development and optimization}

The factors $\mathrm{A}, \mathrm{B}$, and $\mathrm{C}$ and their ranges were given as input to the CCD employed. The software generated 20 runs in total and all the experiments were performed. The experiments conducted and their obtained responses are shown in Table 1. Three responses were selected based on their effect on the separation of drugs. The design model chosen was Quadratic mathematical model as its $p$-value is less than 0.05 and this model was suggested by the design. Different statistical parameters, such as adjusted $r^{2}$, adequate precision, and coefficient of variation (C.V.) obtained from analysis of variance (ANOVA) are shown in Table 2 and all the values were found to be within the acceptance criteria (Beg et al., 2003; Lundstedt et al., 1998; Parajo et al., 1992).

Interaction between the factors and responses and the impact of factors on responses were given by the design in the form of Perturbation plots and response surface plots which are shown in Figures 2 and 3, respectively (Myers et al., 1995). Perturbation plots revealed that factor $C$ has the most important effect on $t R_{1}$ (Fig. 2A), whereas factors $\mathrm{A}, \mathrm{B}$, and $\mathrm{C}$ had the effects on $\mathrm{Rs}_{2,3}$ and $\mathrm{TP}_{1}$ (Figs. 2B and $\mathrm{C}$ ). The interaction of the three factors on responses was predicted by response surface plots as shown in Figure 3 (\% MN concentration in Perturbation plots and response surface plots revealed that factors $\mathrm{B}$ and $\mathrm{C}$ had a large significant effect on separation, whereas factor $\mathrm{A}$, i.e., is $\mathrm{MN}$ concentration, is of little significance.

Derringer's desirability function $(D)$ is used as a critical parameter for optimization. D value near to 1 state that response values are near to the criteria values (Derringer et al., 1980).
Table 2. Statistical parameters obtained from ANOVA for CCD.

\begin{tabular}{ccccc}
\hline Responses & $\boldsymbol{p}$ value & \% CV & $\begin{array}{c}\text { Adequate } \\
\text { precision }\end{array}$ & Adjusted $\boldsymbol{R}^{\mathbf{2}}$ \\
\hline $\mathbf{t R}_{\mathbf{1}}$ & $<0.0001$ & 2.26 & 55.7879 & 0.9906 \\
$\mathbf{R s}_{2,3}$ & $<0.0001$ & 15.52 & 19.3484 & 0.9444 \\
$\mathbf{T P}_{\mathbf{1}}$ & $<0.0001$ & 2.13 & 27.3581 & 0.9637 \\
\hline
\end{tabular}

The criteria for each response which was used in optimization are presented in Table 3. The diagrammatic representation of the response surface obtained for the global desirability function according to the criteria is shown in Figure 4. The maximum desirability value $(D=0.944)$ produced by the conditions (MN concentration of $55 \%(\mathrm{v} / \mathrm{v})$, mobile phase $\mathrm{pH}$ of 5 , and flow rate at $0.8 \mathrm{ml} /$ minute) was chosen for optimization of the method. The experiment was performed using optimized conditions and the obtained and predicted responses are shown in Table 4 and the chromatogram is shown in Figure 5.

\section{Method validation}

The optimized method was validated according to ICH guidelines. Specificity was performed by comparing the chromatograms of the sample and blank and it was found that there were no interferences. Hence, the observed peaks in the sample solution revealed that the method was specific for the three drugs. Linearity was constructed at five levels in the range of 10-30 $\mu \mathrm{g}$ / $\mathrm{ml}$ for all the three drugs with $R^{2}$ of more than 0.999. Standard addition method was used to determine the accuracy and the percent recovery values were found to be $101.62 \%, 99.42 \%$, and $99.52 \%$ for TER, GUA, and AMB, respectively, which were within acceptable 


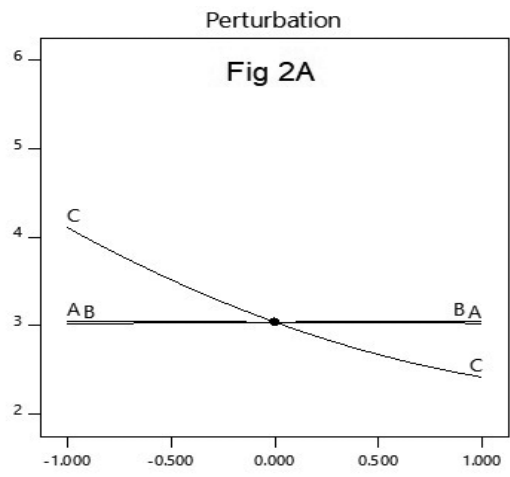

X: Deviation from Reference Point (Coded Units) Y: RT1

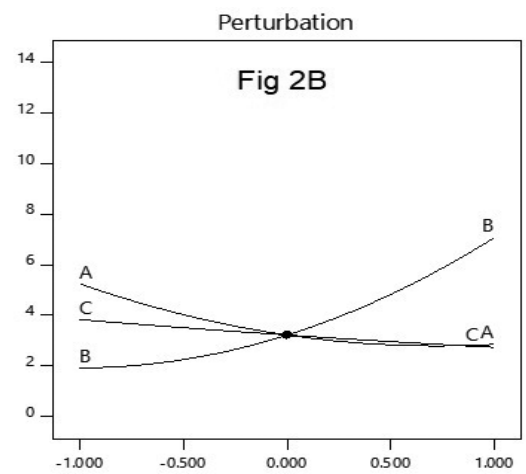

X: Deviation from Reference Point (Coded Units) Y: RS 2,3

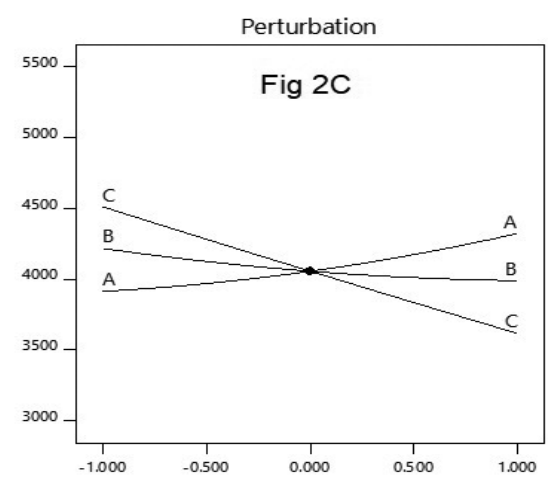

$X$ : Deviation from Reference Point (Coded Units)

Figure 2. Perturbation plots.
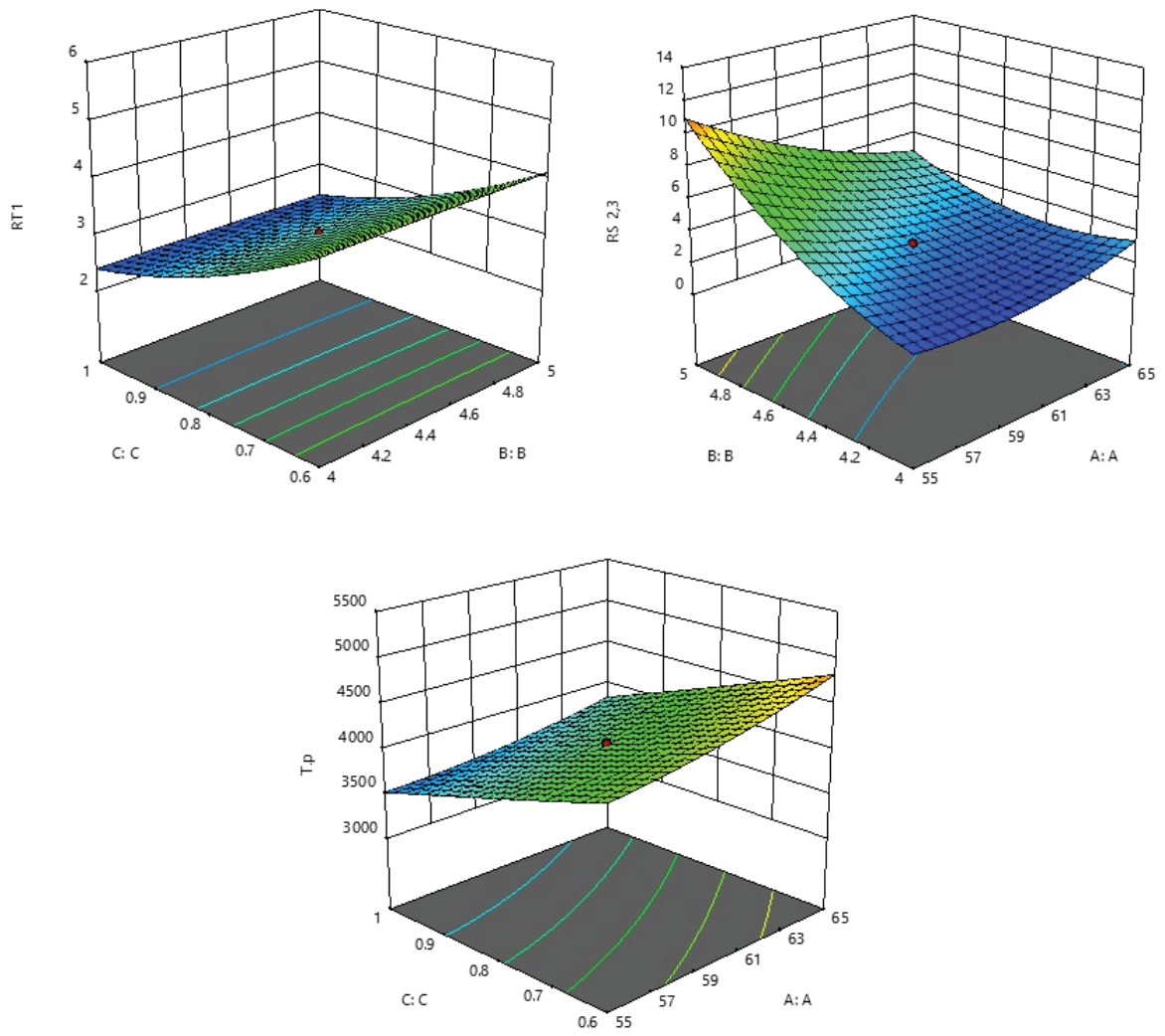

Figure 3. Response surface plots. 
Table 3. Criteria for optimization of individual responses.

\begin{tabular}{cccl}
\hline Response & Lower limit & Upper limit & Criteria \\
\hline $\mathbf{t R}_{\mathbf{1}}$ & 2.158 & 5.232 & Target -3.00 \\
$\mathbf{R s}_{\mathbf{2 , 3}}$ & 1.385 & 12.097 & Maximize \\
$\mathbf{T P}_{\mathbf{1}}$ & 3316 & 5083 & In Range \\
\hline
\end{tabular}

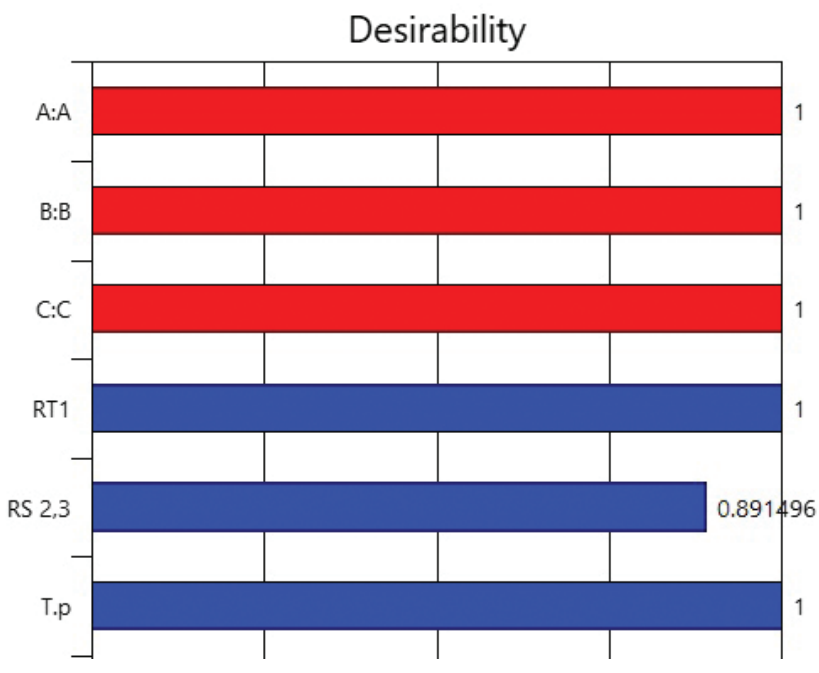

Figure 4. Response surface obtained for the global desirability function.

Table 4. Comparison of experimental and predictive values under optimum condition.

\begin{tabular}{ccccc}
\hline $\begin{array}{c}\text { Optimum } \\
\text { condition }\end{array}$ & Responses & Experimental & Predictive & $\begin{array}{c}\text { Percentage } \\
\text { error }\end{array}$ \\
\hline $\begin{array}{c}\text { MeOH-55 } \\
\text { \%(v/v) }\end{array}$ & $\mathrm{tR}_{1}$ & 3.080 & 3.000 & 2.66 \\
$\begin{array}{c}\text { Mobile phase } \\
\mathbf{p H ~ - 5}\end{array}$ & $\mathrm{Rs}_{2,3}$ & 10.971 & 10.935 & 0.32 \\
$\begin{array}{c}\text { Flow rate-0.8 } \\
\text { ml/minute }\end{array}$ & $\mathrm{TP}_{1}$ & 3799 & 3695 & 2.81 \\
\hline
\end{tabular}

$\mathrm{m} \vee$

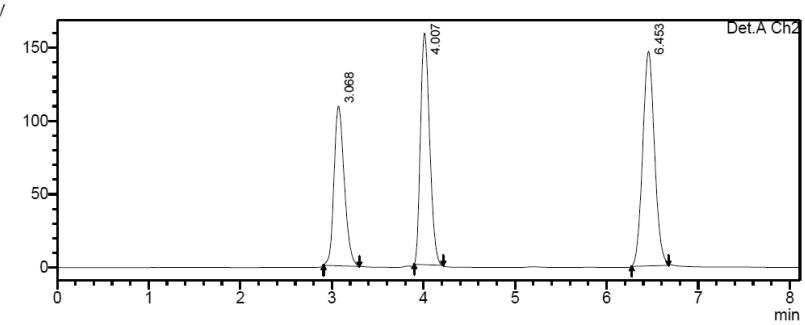

Figure 5. Test sample chromatogram.

ranges of $100 \pm 2 \%$. System precision and method precision were performed and the \% RSD values were found to be less than 2.0. The experiments conducted as per the CCD and their responses revealed the information about robustness. The results obtained by the validation parameters revealed that the developed and optimized method was specific, suitable, linear, precise, accurate, and robust for the simultaneous determination of ambroxol hydrochloride, terbutaline sulfate, and guaiphenesin in their combined dosage form.
Table 5. Assay of marketed formulation by proposed methods.

\begin{tabular}{ccccc}
\hline $\begin{array}{c}\text { Marketed } \\
\text { formulation }\end{array}$ & Samples $^{\mathrm{a}}$ & \multicolumn{3}{c}{ Assay \%(w/w) } \\
\hline & & AMB & TER & GUA \\
& Sample 1 & 99.96 & 102.10 & 98.80 \\
NORVENT & Sample 2 & 98.48 & 100.52 & 98.2 \\
& Sample 3 & 99.56 & 101.08 & 99.10 \\
& Mean \pm SD $^{1}$ & $99.33 \pm$ & $101.23 \pm$ & $98.70 \pm$ \\
& & 0.77 & 0.89 & 0.46 \\
\hline
\end{tabular}

a Three replicate samples of a single syrup container.

\section{Application of the developed method to combined dosage form}

The developed and validated chemometric-assisted RP-HPLC method was applied for simultaneous determination of AMB, TER, and GUA in the syrup dosage form. The sample solutions $(n=3)$ were injected into the HPLC system and their assay results were calculated. The assay results obtained were found to be within the acceptable limits for all the three drugs and are presented in Table 5 .

\section{CONCLUSION}

A chemometric-assisted RP-HPLC method was successfully developed and applied for the simultaneous determination of AMB, TER, and GUA in their combined dosage form and this was considered as the first chemometric method for this combination. The developed method has the advantage of being rapid, precise, accurate, simple, and direct and can be applied for routine analysis in quality control laboratories.

\section{ACKNOWLEDGMENTS}

The authors would like to thank the management and the principal of Sri Padmavathi School of Pharmacy, Tiruchanoor, for providing the facilities to carry out this research work.

\section{CONFLICT OF INTEREST}

This is a non-funding research work. There were no conflicts of interest.

\section{REFERENCES}

Beg Q, Sahai, V, Gupta R. Statistical media optimization and alkaline protease production from Bacillus mojavensis in a bioreactor. Process Biochem, 2003; 39(2):203-9.

Derringer G, Suich R. Simultaneous optimization of several response variables. J Qual Technol, 1980; 12(4):214-9.

Ghosh A ,Mandal S. K, Ghosh S, Deb S, Development and validation of RP-HPLC method for simultaneous determination of Terbutaline sulphate, Guaiphenesin and Ambroxol hydrochloride from an oral liquid. Indian Drugs, 2016; 53:53-6.

Giriraj P, Sivakkumar T. A rapid - chemometrics assisted RPHPLC method with PDA detection for the simultaneous estimation of ofloxacin and nimorazole in pharmaceutical formulation. J Liq Chromatogr Relat Technol, 2015; 38(8):87-9.

Kimbahune R, Sunil K, Kabra P, Delvadiya K, Surani S. Spectrophotometric simultaneous analysis of ambroxol hydrochloride, guaifenesin and terbutaline sulphate in liquid dosage form. Int J Pharm Sci Rev, 2011; 8:004.

Lakshmi Narasimha Rao L, Krishnaiah C, Sudheer Babu K, Padmaja Reddy K. Development and validation of a stability-indicating LC method for simultaneous determination of related compounds of guaifenesin, 
terbutaline sulphate and ambroxol $\mathrm{HCl}$ in cough syrup formulation. J Saudi Chem Soc, 2014; 18:593-600.

Lundstedt T, Seifert E, Abramo L, Thelin B, Nystrom A, Pettersen J, Bergman R. Chemom. Intell Lab Syst, 1998; 42(1-2):3-40.

Myers RH, Montgomery D. Response surface methodology. John Wiley \& Sons Inc., New York, NY, 1995.

National Center for Biotechnology Information. PubChem Compound Database; CID $=3516$, https://pubchem.ncbi.nlm.nih.gov/ compound/3516 (Accessed 18 December 2018).

National Center for Biotechnology Information. PubChem Compound Database; CID $=31620$, https://pubchem.ncbi.nlm.nih.gov/ compound/31620 (Accessed 18 December 2018)

Parajo JC, Alonso JL, Lage MA, Vazquez D. Empirical modeling of eucalyptus wood processing. Bioprocess Eng, 1992; 8:129-36.

Sivakumar T, Manavalan R, Muralidharan C, Valliappan K. Multi-criteria decision making approach and experimental design as chemometric tools to optimize HPLC separation of domperidone and pantoprazole. J Pharm Biomed Anal, 2007; 43:1842-8.
Sree Janardhanan V, Manavalan R, Valliappan K. Chemometric technique for the optimization of chromatographic system: simultaneous HPLC determination of Rosuvastatin, Telmisartan, Ezetimibe and Atorvastatin used in combined cardiovascular therapy. Arab J Chem, 2016; 9:S1378-87.

How to cite this article:

Palur K, Koganti B, Archakam SC. Chemometric-assisted RP-HPLC method for the simultaneous determination of ambroxol hydrochloride, terbutaline sulfate, and guaiphenesin in combined dosage form. J Appl Pharm Sci, 2019; 9(09): 092-097. 